\title{
DISTANCE EDUCATION FOR PEOPLE WITH VISUAL IMPAIRMENTS
}

\author{
MariaLiakon[liakos7@hotmail.com],Evaggelia Manouson[manousoug@gmail.com],Hellenic Open \\ University, Greece
}

\begin{abstract}
This paper studies the standards of higher Distance Education, focusing on the Hellenic Open University, for people who have visual impairments, so that it becomes fully accessible and thus helps reduce social exclusion. Specifically, it aims to study the operational context of Distance Education, the possibilities that modern technology provides the educational needs of the visually impaired and the factors that prevent their full social integration.
\end{abstract}

\section{Introduction}

Distance learning constitutes a method suitable for people with disabilities and, more particularly, for people with a visual impairment, as it can contribute to their easier integration into the educational and social environment. The philosophy underlying distance learning is the creation and provision of alternative educational opportunities, as well as the open access to these opportunities for everyone so that the ideal of open education may be fulfilled (Lionarakis \& Likourgioti, 1998, p.30). Providing educational opportunities to everyone is linked directly with the opportunity to access education and, as a result, with the widening of the constraints and the potentials of distance learning through the utilization of various methods and means. Such a widening though needs to take into account people with any kind of disability, and to investigate the ways in which these people can be involved in distance learning (Garrison, Schardt \& Kochi, 2000). Besides, this type of education is already developed to such a level that with the utilization of ICT (Information and communication technologies) offers innovative applications as well as alternative learning opportunities (Lionarakis, 2004).

The goal of the present research is to define the standards of higher education for people with a visual impairment, so that education becomes fully accessible and contributes to the limitation of social exclusion. In further detail, what is sought is the study of the educational needs of the visual impaired as well as the factors which contribute to their social exclusion, functioning as an obstacle to their complete social integration as far as education is concerned, and also the study of the framework within which distance learning functions and the opportunities contemporary technology provides to the educational process.

The specific goals of this research are to define the particularities of the visual impaired as far as their participation in the educational process is concerned, the means with which these particularities can be met, and to study the distance learning offered to them within the context of the Greek higher education. In addition, the widening of the access of the visual impaired constitutes another objective of this research, and particularly in the Hellenic Open University as an institution which provides higher distance learning. In more detail, this goal involves the widening of supporting mechanisms of the Hellenic Open University and of the available devices of supportive technology which people with vision problems use within the framework of distance education, so that the technological standards of the institution which make it completely accessible are defined. Based on the above, the following research questions have come up: 
- Which are the factors that need to be taken into account for the accessibility of the visual impaired in higher distance education and for the reduction of social exclusion in education?

- What are the educational needs of people with reduced vision who participate in distance educational programs, and in which ways are these needs met by the HOU?

- What is the policy of the HOU with respect to the access and participation of people with vision problems in its programs and what are the ways in which HOU can contribute to the extermination of social exclusion in education for people with disabilities, and more particularly, with reduced impaired vision

\section{Social exclusion and people with vision problems}

The main factors leading the visual impaired to social exclusion are their challenges to integrate the non-verbal interpersonal expressions such as gestures, smiles, nods and also their difficulty to respond to input and interact with the environment. Also, a very important cause of social exclusion is the lack of encouragement toward the visual impaired by their social environment, an act which would reinforce their social involvement (Van Hasselt, 1988). The encouragement and facilitation of people with reduced vision can be accomplished by realizing that these people have a greater need for the provision of information when compared to those with no vision difficulties. Especially in our contemporary "information age," the lack of access to a wide range of information is considered more and more one of the most critical factors of social exclusion (Moore, 2000).

In the age of technology, people with disabilities should be able to live with dignity and selfworth. Social, technological, political and economic barriers continue to limit the full participation of children and adults with disabilities in the digital age, keeping them behind other members of society without disabilities (Dobransky \& Hargittai, 2006; Ellcessor, 2010). Those people who now enjoy good health may become disabled, whether as part of the aging process or unexpectedly at any age (US Department of Commerce, 2013).

The key to the successful access of the visual impaired to all information involves ensuring proper information, at the proper time and in the proper form (Willetts, 1993). Technological progress renders the provision of information to the visual impaired possible, and also in a manner which is easy to access. On the other hand, though, while the commercial sector invests enormous amounts of money in advanced computer systems, most people with a visual impairment live in a condition of being deprived of information essential to meet their basic natural, psychological and emotional needs (Amedeo \& Speicher, 1995).

With respect to the participation of the visual impaired in the labour force, these people exhibit a positive will for labour, despite the fact that the unemployment rate of the particular group of people is globally much higher than that of the general population (Robin, 2002), even in the advanced and developed countries (La Grow, 2004). The unemployment rates are also due to the fact that employers have created a series of obstacles in the employment of the visual impaired (Crudden et al., 1998; Wolffe \& Candela, 2002). Apart from the financial problems, the visual impaired are also faced with prejudice and discrimination at a social level. The possible marginalization because of such phenomena reduces chances of the visual impaired for social reengagement and leads to the potential of developing problematic relationships or psychological problems (Kotsopoulou, 2011).

The solution which is proposed for tackling the social exclusion of people with a visual impairment deals with the facilitation of their information, that is, the open access to the total range of information. This can be accomplished via the provision of educational opportunities in 
combination with the use of ICT. At the same time, the open access to education of the visual impaired contributes to the tackling of unemployment, since, through the proper training and education, they will acquire professional skills and competences.

\section{Training of the visual impaired}

The training of the visual impaired involves different teaching methods and teaching means when compared to those used for people without such problems (Hiourea, 1998), as the loss of vision affects the way in which an individual performs various everyday activities, receives information, moves, communicates, and functions in his/her environment in general. In greater detail, the training of the visual impaired has, as its main goal, the facing of the limitations that are caused by vision disability, by providing opportunities for the development of various supplementary and counter-balancing competencies, so that the potential delays of development caused by it are significantly reduced.

With respect to its historical development, the training of people with visual impaired began in the late $18^{\text {th }}$ century, when the first school for the blind was established in Paris (McCall, 1997), and in the $19^{\text {th }}$ century there has been a spread of schools for the visual impaired in Europe, but also in America and Australia (Kelly \& Gale, 1998). Up until today, significant progress has occurred in the field of training the visual impaired, first and foremost by the accredited international learning centre of Hadley. This school specializes its students in issues of training people with blindness or reduced vision 14 years old or older, and also in issues of support by their family environment of (Support services for the Blind and Visual Impaired, 2012).

There are four specialized schools in operation in Greece; in Athens, Thessaloniki, Patra and Ioannina, which, however, provide only elementary level education and training (Sperl, 2001). As far as higher education is concerned, the establishment of the HOU has been a critical point for the visual impaired, since the institution accepts and supports students with disabilities (Kritikou \& Koutsoumpa, 2011).

In fact HOU is the only institution that offers entirely distance education, although in recent years some conventional Greek universities offer distance learning short courses.

\section{Distance training}

Distance training can be applied in all the levels of education, as one of its fundamental characteristics is the educational material which is especially designed as well as the utilization of ICT (Ko \& Rossen, 2001). At the same time, a basic requirement for the effectiveness of distance training is the frequent communication between the teachers and the students, as well as supporting activities applied by the teacher him/herself, who functions in an encouraging manner as an advisor (Race, 1989).

Compared to the conventional types of training, distance training manages to overcome a number of restrictions, such as the mandatory presence of the student in the space where the class takes place. In addition, the public to which it is targeted is much wider, due to the fact that this type of training offers more educational opportunities through the utilization of ICT (Lionarakis \& Likourgiotis, 1998; Lionarakis, Panagiotakopoulos \& Xenos, 2005; Ali, 2008).

In greater detail, within the framework of this type of training, learning is based on the personal study of the educational material by the trainee, and its effectiveness depends, to a great extent, on the communication and cooperation of the latter with the trainer. At the same time, distance training needs to be perfectly designed, have clearly defined teaching objectives, and analyze the pedagogical requirements of the educational process (Moore, 1993; Holmberg, 2005; Peters, 
1993). Moreover, a basic characteristic of distance training is that it is based on three structural elements: the trainer, the trainee, and the training material (Lionarakis, 2004).

\section{Distance training of the visual impaired}

The above characteristics of distance training revolve, to a great extent, around the training of the visual impaired, not only because they are given the opportunity to attend a given program from their personal space, thus avoiding transportation, but also because of the opportunity to use supportive technology with a software that widens the screen (CATEA, 2006). It is thus clear that the accessibility of distance education programs by the visual impaired is defined by the existence of relevant educational material, central characteristics of which should be the maximum clarity and usability (Arditi, 2012).

However, what has come up from studies on the level of accessibility of distance education programs is that this education does not fully respond to the needs of the visual impaired. The research data gathered (Jacko, 2011; Fitzpatrick \& McMullen, 2008; Karahlani \& Sourmaidou, 1998; Presley, 2009; Skantzouri, 2008) show that, despite the fact that many universities today extend their programs to distance learning ones, this extension does not seem always to include educational material in a form that would address the people with this kind of disability. The most frequent and important problems that the visual impaired faces during their studies in a typical distance training program are:

- the lack of access to graphic material (diagrams, charts etc.), an obstacle which often leads to an almost exclusive selection of studies in humanities;

- the non-trustworthy supportive equipment;

- the lack of specialized educational personnel on vision disability;

- the lack of an intermediary person who would facilitate the studies of the visual impaired, and

- the inability of many libraries to address the demands of these students, as they do not possess material in an alternative form.

\section{Research methodology of this essay}

The qualitative data of the present research were gathered through interviews. More particularly, qualitative, non-structured open-question interviews were conducted, as the research question refer to human cases for which information is sought to be drawn, presented from the perspective of each interviewee (Yin, 1989). In particular, different interview tools (questions) were designed, depending on the features of every subject of the research, and with the goal of collecting data through these questions and formulating opinions and statements concerning the role of distance learning, the conditions of studying or working within the framework of HOU, with the total of the activities and processes that take place and thus with the overall function of $\mathrm{HOU}$, while it was also sought to collect opinions concerning the effectiveness of all these processes. The interview questions used in this research aim at addressing issues from, the viewpoint and the perception of every subject individually, issues significantly affected by the characteristics of each subject. During the design, emphasis was placed so that the research questions were answered broadly.

The subjects of the research are six individuals, who meet two basic and necessary requirements: i) they are directly related to distance studies in the Open University and ii) with students with a visual impairment. More particularly, a HOU student was sought and tracked, two members of the Advisory Scientific Personnel (ASP) who work together or had worked with students with a visual impairment, a librarian, a worker in the Material Dissemination Division and a worker of 
the HOU administration. For the approach of the selected subjects, a brief letter was composed, which included the relevant references and information concerning the research which would then take place.

\section{Empirical research results}

According to the analysis of the data of the interviews conducted for the present research, and in relation to the first research question which refers to the factors that need to be taken into account about the accessibility of people with reduced vision to higher distance education and the reduction of social exclusion in education, the interviewees seem to agree on several points, while appearing on other ones to approach the issue from a different perspective. As an example, several excerpts of the interviews are cited:

"I chose HOU because studying and everything can be done from home, I do not need to go to a university."

(Excerpt of the answer of a student to the question 'why he chose HOU')

"The problems I face primarily deal with the material."

(Excerpt of a student to the question 'whether he believes that people with reduced vision are faced with challenges in education')

"In the Open University of Cyprus, the Students with Special Requirements like myself do not need to attend meetings, but five meetings are recorded and sent to their computers. Afterwards, they do not go to the University for the Exams, but ask and answer questions through Skeype."

(Excerpt of the answer of a student to the questions 'whether he faces difficulties in the access of HOU educational processes')

"They should give us any book for assistance in electronic form. I would say that they should suggest books that exist in electronic form to everyone even in PDF, I don't mind, I can turn those into word files."

(Excerpt of the answer of a student to the question 'what can be done so as to overcome the problems in access)

"Imagine that there were about thirty people inside the class a few years ago. In the first years no one spoke to me! No-one!"

(Excerpt of the answer of a student to the question 'whether he faces any other kind of problems in HOU')

"In the past I had done an assignment in HOU and received 5.5 and a comment was that "there were sources missing from your essay." I mean, they need to realize a few things."

(Excerpt of the answer of a student to the question 'are there any difficulties while composing an essay')

"This person (student with a vision impairment often emails me with various questions and I immediately reply. Because I take care of him (I take care of everyone) a bit more. 
(Excerpt of the answer of ASP1 to the question 'did you have any particular information/guidelines from HOU concerning the participation of people with disabilities)

"The support students receive, the technological support if something is needed, the cognitive support with respect to people with learning disabilities or people with special needs"

(Excerpt of the answer of ASP2 to the question 'did you have any particular information/guidelines from HOU or another university in which you worked about the participation of people with disabilities')

"They can bridge this social gap that exists concerning the social restriction through let's say social media, I think it can do that, it can do it online, it can do it through the courses offered in HOU”

(Excerpt of the answer of ASP2 to the questions 'does distance training contribute to the tackling of social exclusion')

"You need to support them because they have-let's say-different kinds of needs and psychological issues and others."

(Excerpt of an answer of ASP2 to the questions about 'what do you believe should be the policy of HOU concerning the participation of people with disabilities')

"There should be an office or a small organization within HOU which deals exclusively with these students and their needs, and educates any teacher."

(Excerpt of an answer of ASP2 to the same question)

"Creation of hardcopy educational material in Braille form, and purchasing of new educational material which will facilitate the access of people with disabilities in the processes of education"

(Excerpt of the answer of a librarian to the question 'suggestions to HOU for the effective fulfilment of the demands of people with a vision impairment

"I would imagine that since they have not complained, there is no problem."

(Excerpt of the answer of the person in charge of the Material Dissemination Unit in a relevant question)

"You should go to DASTA of...HOU they will tell you if they can find some kind of employment for graduates with a vision impairment"

(Excerpt of the answer of an administration worker to the questions 'can HOU contribute to the reduction of social exclusion for people with disabilities')

"- Would you recommend something that HOU could do, in general, so as to meet the needs of...these people?

- No, no, ok, the number of the students is not big."

(Excerpt of a conversation with an administration employee)

According to the research findings, the factors that need to be taken into account can be briefly presented in the following table. 
Table 1:

\begin{tabular}{|c|c|c|}
\hline Fields of interest & \multicolumn{2}{|c|}{ Factors that need to be taken into account } \\
\hline \multirow[t]{5}{*}{$\begin{array}{l}\text { Issues of the educational } \\
\text { process }\end{array}$} & \multicolumn{2}{|c|}{$\begin{array}{l}\text { Potential presence for people with visual impairments through } \\
\text { teleconferencing }\end{array}$} \\
\hline & \multicolumn{2}{|c|}{$\begin{array}{l}\text { Provision of complete educational material in an accessible form for } \\
\text { people with visual impairments }\end{array}$} \\
\hline & \multirow{3}{*}{$\begin{array}{l}\text { Frequent and constructive } \\
\text { communication of the teacher with } \\
\text { the students with visual } \\
\text { impairments }\end{array}$} & Resolving questions \\
\hline & & Provision of feedback \\
\hline & & $\begin{array}{l}\text { Support during the studies } \\
\text { (cognitive, psychological, etc) }\end{array}$ \\
\hline \multirow[t]{3}{*}{ Issues of HOU policy } & \multicolumn{2}{|c|}{$\begin{array}{l}\text { Promotion of the building and development of social relationships } \\
\text { and social activities for the students with vision disability }\end{array}$} \\
\hline & \multicolumn{2}{|c|}{$\begin{array}{l}\text { Care for the professional rehabilitation of students with impaired } \\
\text { vision }\end{array}$} \\
\hline & \multicolumn{2}{|c|}{ Covering the special needs of students with disabilities } \\
\hline
\end{tabular}

With respect to the second research question and more particularly the educational needs of students with vision problems, but also the ways in which these are covered within the framework of $\mathrm{HOU}$, the findings of the analysis primarily focus on the educational material and on the access the particular students have on it.

The following table summarizes the findings.

Table 2:

\begin{tabular}{|l|l|}
\hline Educational needs & Ways to meet the educational needs within the framework of HOU \\
\hline \multirow{5}{*}{$\begin{array}{l}\text { Educational } \\
\text { material }\end{array}$} & $\begin{array}{l}\text { Provision of educational material to the student in electronic form, by the } \\
\text { tutors }\end{array}$ \\
\cline { 2 - 2 } & $\begin{array}{l}\text { Transformation of the educational material to an electronic form which is } \\
\text { compatible with the software the student uses by the administration } \\
\text { employee }\end{array}$ \\
\cline { 2 - 2 } & $\begin{array}{l}\text { Option of communication between student, tutors-counsellor, and } \\
\text { administration employee at any time }\end{array}$ \\
\hline Evaluation & $\begin{array}{l}\text { Development of special evaluation criteria on behalf of the teacher, which } \\
\text { respond to the different amount of effort the particular student makes }\end{array}$ \\
\hline $\begin{array}{l}\text { Flexibility in } \\
\text { physical presence }\end{array}$ & $\begin{array}{l}\text { Conducting oral exams on the space of the library (HOU) } \\
\text { in the educational platform (US University) }\end{array}$ \\
\hline $\begin{array}{l}\text { Distribution } \\
\text { procedures of the } \\
\text { necessary software } \\
\text { Supernova }\end{array}$ & $\begin{array}{l}\text { Creation of a properly equipped "work station" in the space of the library, } \\
\text { where computers with the Supernova software are available }\end{array}$ \\
\cline { 2 - 2 } & \begin{tabular}{l} 
Distribution of the software to the students who have applied by the MDU \\
\hline
\end{tabular} \\
\hline
\end{tabular}

With respect to the third research question which deals with the policy of HOU concerning the access and participation of the people with impaired vision in its programs and the ways in which the particular educational institution contributes to the reduction of the phenomenon of social exclusion (third research question), most interviewees agree that HOU does not provide relevant training to the employees and professors for the support of similar students.

For the improvement of the policy and function of HOU as far as the widening of the access of people with disabilities is concerned, what was suggested was that the entire educational material be provided in electronic form, compatible to the software used by students with vision problems impaired vision, that it is also transformed to Braille, and also that the provision of the educational material in the proper form should be accompanied by the relevant technical equipment for the professors, as well as relevant training for these issues. 
With respect to the library services, the suggestions involve the adjustment of the departmental websites so that they are accessible in a form which is readable and meets the demands of the particular group of people, and also the upgrading of the work station inside the library as well as the technical equipment of the institution. These upgrades can be accomplished through the provision of new technical equipment. In addition, the Hellenization of the application Screen reader is recommended, so that the reading software can be freely distributed to the HOU students with impaired vision.

\section{Discussion of findings}

What can be drawn from the research findings is, first, that the individuals who participated in the research demonstrate diversity in their perception of the phenomenon of social exclusion. This is due to each individual's role and the personal experiences s/he possesses, elements which certainly affect that perspective with which they approach the issue. As a result, each one focuses on different factors that need to be taken into account, so that the access of people with disabilities is increased, and, more specifically, the access of people with vision problems impaired vision to the higher distance education. This widening of the access leads to the provision of further educational opportunities than those that people with disabilities typically receive, thus contributing to the diminishment of the educational and, more broadly, social exclusion. The subjects of this research agree on this point, as well as on the theory that deals with the connection between education and the reduction of social exclusion.

Another issue in which all the interviewees seem to agree is the provision of fully accessible educational material to people with vision problems impaired vision. The severity of the issue was demonstrated by the extent of the answers given by the students with impaired vision and of the members of ASP, and also by the fact that the answers of the HOU administration employee were centred on the transformation of the educational material in a form accessible to people with impaired vision.

At the same time, the paramount importance of communication between teachers and professors in distance learning was highlighted, even more so with the students with vision problems impaired vision. What is also noteworthy is the fact that the student who participated in the present research feels satisfied with the communication with his professor and her supportive mechanisms - in cooperation with the 'technician' who literally is the employee of the administration - to the point that he almost neglects the total absence of fully organized and specialized supporting mechanisms on behalf of HOU on an institutional level. On the other hand, the professors themselves in their interviews recognized that their role in distance learning is distinctive and largely different from the one their counterparts have in conventional universities. This differentiation is due to the frequency and the particularity of the communication they develop with their students.

Apart from a common perception of their roles, the two professors seemed to share different experiences concerning their cooperation with students with vision problems and their particular educational needs. This differentiation is probably due to the different framework this cooperation occurred, since the first professor draws information from the framework and environment of HOU, whereas the second one from her education in a university in the U.S.A. As a result, the perception of the former is reduced to sending accessible educational material to the student and does not recognize the effectiveness of actions on an institutional level. On the contrary, the second professor recognizes the supporting practices both on a personal and on an institutional level. 
The above difference, coupled with the realization that the head of the material distribution department possesses only elementary or standard knowledge with respect to the specialized needs of people with disabilities, and more particularly those of students with vision problems impaired vision, constitute a sign of a lack of relevant information or training of the HOU staff. Besides, most interviewees clearly stated that this kind of training does not exist, which is largely different from the declaration of the institution that its function is such that it can accept people with disabilities and meet their educational needs. Concerning the students with impaired vision in particular, the organization of the function mainly concerns the distribution of the Supernova software, a process which is relatively time-consuming and costly, and to the maintenance of the equipment of the library, which is of a relatively good level, but can certainly be improved and updated. Thus, although the HOU appears to take into consideration and care for people with disabilities, the reality is that the function of HOU has not officially developed satisfactory and effective supportive mechanisms for them.

This conclusion is drawn from comparing HOU with the Open University of Cyprus and the U.S.A. University where one of the professors taught in the past. In the first case, HOU lags behind in the facilitation of people with disabilities; since it does not reduce their mandatory transportation for the attendance of face to face tutorials. HOU has, with the exception of the Supernova software--installed with instructions for use, the library's workstation to serve students with vision impairment. The workstation provides the computers with a screen reader, allowing display screen in Braille or a display of data, enlarged up to 32 times. It also has improved software performance of the speech output of the display data, special printer WinBraille with the printing of even mathematical equations (printable files: doc, pdf), an enlargement device showing the image display panel ability to create contrasts, colour inversion and magnification up to 50 times. But the Foundation website needs updating to come in proper readable format in order to serve this group of individuals, but also needed is the upgrading of the workstation within the library and the technical equipment of the institution (procurement of new equipment, localization application Screen Reader).

In the second case, the distance training program that the U.S.A. University developed (a traditional institution of higher education), utilized more new technologies compared to HOU. In further detail, the operation of a specially designed educational platform was provided, as well as the labour of specialized technical staff, the establishment of an office for the support of students, staffed with specialized platform (carrying online communicating with courses anytime - Virtual Training Environment), cooperation and employment of specialized technical personnel, setting up student support office staffed with qualified advisory staff and informing all stakeholders in the educational process of the appropriate assistance for every problem. In the absence of people with low vision, the tutor can provide them with various electronic, audio or printed depending on the desire of the learner as said in the meeting, and following consultation with the -tutor counsellor, so as to have access to information and to be part of a study group. These are the distinctions between the U.S.A. University and HOU.

Even in terms of the teaching methods applied at HOU, despite the fact that HOU as an institution adopts the philosophy of distance learning and despite the willingness of the professors to support the studies of persons with vision problems impaired vision, a number of malfunctions emerge. A typical example of this is the fact that the student with vision problems impaired vision and his professor expressed a totally different opinion concerning the criteria and results of his evaluation. This may have happened as there are no officially defined assessment criteria for evaluating students with reduced vision, or because the essential supportive mechanisms are not available during these people's studies, such that the establishment of differentiated assessment criteria would not be required. 
Lastly, it is worth noting that all the employees and working partners of HOU believe that the students with vision problems impaired vision attending a training or educational program are satisfied by the way they themselves and the institution treats them, as no one has ever made a complaint about their services or the solution given to their problems. What contributes to this is not only the willingness of every employee or professor to assist as much as possible, even outside his/her working hours, but also the awareness of the students themselves that the supporting structures of the institution are limited. At the same time, the fact that HOU does not provide specialized educational programs or processes for students with disabilities, as well as the fact that the typical problems of the students with vision problems impaired vision are effectively resolved through the personal actions of a given employee is due to the fact that the number of these students is very small. What can be argued, though, is that should the university have better and more effective supporting mechanisms and information about these issues, and then perhaps the number of the people with disabilities attending a HOU educational program will increase.

- mechanisms, devices or otherwise Assistive Technology devices to use as part of their training is (Kotsiatis \& Panayiotou, 2004, p.38):

- Orientation and mobility aids

- Visual aids, such as special prescription glasses, magnifiers small telescopes

- Aids serving to stimulate vision, such as lecterns books, lamps, markers, print slides, books with enlarged letters, bookmarks, cards with sharp delineation, measurement tools and special shields to protect the eyes from light

- Aids serving stimulate touch, as is the table cyber-number the table for design raised signage, paper with embossed striping, the abacus Kranmer, the writing drivers and restraints

- Aids serving to stimulate the hearing, such as talking audio books, tape recorders, components for modulating the playback speed of sound and headphones fitness equipment

- Digital devices, such as computers, talking calculators, the voice synthesizer, closed circuit $\mathrm{TV}$, the zoom system and information on these issues, possibly the number of people with disabilities who would attend an educational program of the HOU would have been larger.

\section{Conclusions}

What emerges from the analysis of the relevant research data is that, first, the accessibility of distance training of people with vision problems impaired vision is defined and determined to a great extent by the form of the educational material, which should be in electronic form and in the form of files which allow greater focus and/or voice reading (e.g. doc files). It is thus confirmed that the educational material constitutes the fundamental characteristic of distance training programs (Ko \& Rossen, 2001), which should be accessible to people with disabilities. Furthermore, other prerequisites of distance training for people with vision problems impaired vision are the non-mandatory attending of meetings between these students and the professor, so that the limitations and restrictions of conventional education are overcome (Lionarakis \& Likourgiotis, 1998), the training of the educators with respect to the development of supporting actions for students with vision disability during the educational process (Race, 1989), the option to record and send the class material, the supportive equipment, the assistive technology such as visual aids, aids stimulation of visual, tactile, and auditory function and electronic devices (enlargers CCTV, Readers screen, programs 'read' the content of the screen and guide the user in vocal use of Conversions from Text to Speech and Magnification Display Software (screen magnification software) for the utilization of ICT which is also a fundamental feature of this type 
of training and education (Ko \& Rossen, 2001) as well as the proper orientation of the surrounding space (seminar rooms, teaching rooms, libraries, etc).

Should the above prerequisites be met, distance education can contribute to the provision of equal educational opportunities to people with disabilities and, more particularly, to people with vision disabilities so that it contributes to the diminishment of social exclusion, which occurs due to the limited access of these people to information and their deficient educational training because the insufficient provision of special equipment as well as the lack of training of staff (Van Hasselt, 1988; Moore, 2000; Robin, 2002; La Grow, 2004; Crudden et al., 1998; Wolffe \& Candela, 2002; Kotsopoulou, 2011). However, so that this opportunity is addressed, the institutions which develop distance training programs need to place considerable importance on the various factors which contribute to the effective function of these programs. From these factors, the main one, as was shown above, is that of utilizing information and communication technologies, as well as using supportive technological equipment, relevant and specially designed for people with vision problems impaired vision.

At the same time though, the need of people with vision impairment for human interaction and communication with the rest of the participants in these programs, and primarily with their professor, should not be undermined.

The findings of the present research, however, lead to more particular findings concerning the Hellenic Open University, which is predominantly an institution of distance education and training. More precisely, it was shown that HOU receives people with disabilities to attend its educational programs, thus offering them educational opportunities, and at the same time contributing to the diminishment of social exclusion. Moreover, since we are referring to an institution of distance education and training, HOU employs this kind of educational philosophy and makes considerable efforts so as to apply the most proper teaching methods possible. Despite all these efforts, though, HOU has no specialized programs or expertise staff for students with disabilities and, more particularly, for students with vision problems impaired vision. Along similar lines, the design, structure, and organization of the function of HOU lacks training, information, and guidance of the educational staff with respect to the management of similar students and the meeting and fulfilment of their special educational demands. As a result, the need to redefine and improve the policy of HOU is considerable, in terms of these issues and the practices HOU applies for its students, irrespective of their physical condition.

\section{References}

1. Ali, M. (2008). Connecting People with Disabilities: ICT Opportunities for All. Munich Personal RePEc Archive Retrieved from http://mpra.ub.uni-muenchen.de/17204

2. Alper, M. (2014). Digital youth with disabilities, reports on digital media and learning. The John D. and Catherine T. MacArthur Foundation. Retrieved from https://www.academia.edu/7330242/Digital_Youth_with_Disabilities

3. Amedeo, D. and Speicher, K. (1995). Essential environmental and spatial concerns for the congenitally visually impaired. In Journal of Planning Education and Research, 14, (pp. 113-122).

4. Arditi, A. (2012). Designing for people with partial sigh. Retrieved from http://www.lighthouse.org

5. Crudden, A.; McBroom, L.; Skinner, A.; Moore, J. (1998). Comprehensive examination of barriers to employment among persons who are blind or visually impaired. Mississippi State: Rehabilitation Research and Training Center on Blindness and Low Vision, University of Mississippi.

6. Dobransky, K., and Hargittai, E. (2006). The Disability Divide in Internet Access and Use. In Information Communication and Society, 9(3), (pp. 313-334). 
7. Ellcessor, E. (2010). Bridging Disability Divides. In Information Communication and Society, 13(3), (pp. 289-308).

8. Fitzpatrick, D. and McMullen, D. (2008). Distance Learning of Graphically Intensive Material for Visually Impaired Students. In K. Miesenberger, J. Klaus, W.L. Zagler \& A.I. Karshmer (eds.), ICCHP 2008, LNCS, vol. 5105, (pp. 219-225). Heidelberg: Springer.

9. Garrison, J.A.; Schardt, C.; Kochi, J.K. (2000). Web-based distance continuing education: A new way of thinking for students and instructors. In Bulletin of the Medical Library Association, 88(3), (pp. 211-217).

10. Hiourea, R. (1998). Introduction to the training of blind people in Greece. Athens: Lihnos.

11. Holmberg, B. (2005). The evolution, principles and practices of distance education. In U. Bernath et al. (eds.), Studien und berichte der arbeitsstelle fernstudienforschung der Carl von Ossietzky Universität Oldenburg, vol. 11.

12. Catea (2006). Individuals who are Blind or have Low Vision. Retrieved from http:/ /www.catea.gatech.edu/search.php?cx $=012925944374153088534 \% 3 A q 4 x \_n i h p i t u \& q$ $=$ Individuals + who + are + Blind + or + have + Low + Vision\&sa $=$ Search\&cof=FORID $\% 3$ A11

13. Jacko, V. (2011). Let's Give the Blind Better Access to Online Learning. In Chronicle of Higher Education, 57(36), (pp. 30-35).

14. Karahlani, D. and Sourmaidou P. (1998). System trials for the access of blind and reduced-vision readers in libraries. Polyplano Euroconsultants, Thessaloniki.

15. Kelly, P. and Gale, G. (1998). Towards excellence-effective education for students with vision impairments. Sydney: Royal Institute for Deaf and Blind Children.

16. Ko, S. and Rossen, S. (2001). Teaching Online a Practical Guide. New York: Houghton Mifflin Company.

17. Kotsopoulou, M. (2011). E-learning for people with disabilities. MA Dissertation in the University of Macedonia, Thessaloniki.

18. Kritikou, S. and Koutsoumpa, M. (2011). Open and distance higher education and people with disabilities. The case of the Greek Open University. In The Journal for Open \& Distance Education and Educational Technology, 7(2), (pp. 88-98).

19. La Grow, S.J. (2004). Factors that Affect the Employment Status of Working-Age Adults with Visual Impairments in New Zealand. In Journal of Visual Impairment \& Blindness, 98(9), (pp. 546-559). Retrieved from http://files.eric.ed.gov/fulltext/EJ735502.pdf

20. Lionarakis, A. (2004). Open and distance education and learning processes, in Open and Distance Education: Pedagogical and technological applications. Retrieved from http://class.eap.gr

21. Lionarakis, A. and Likourgiotis, A. (1998). Open systems of higher education. In A. Kokkos, A. Lionarakis \& C. Matralis (eds.), Open and distance learning. Institutions and functions. Vol. A'. Patra: Hellenic Open University.

22. Lionarakis, A.; Panagiotakopoulos, C. and Xenos, M. (2005). Open and Distance Learning: tools of information and communication technologies for effective learning. In A. Lionarakis (ed.), Open and Distance Learning, Pedagogical and Technological Application. Hellenic Open University.

23. McCall, S. (1997). Historical perspectives. In H. Mason, S. McCall, A. Arter, M. McLinden, \& J. Stone (eds.), Visual impairment access to education for children and young people, (pp. 55-67). London: David Fulton. 
24. Moore, M. (1993). Theory of transactional distance. In D. Keegan (eds), Theoretical principles of distance education. London: Routledge.

25. Moore, N. (2000). The information needs of visually impaired people. Acumen.

26. Ogbonnaya, D.I. (2012). The roles of ICT development in open and distance education: Achievements, Prospects and Challenges.

27. Peters, O. (1993). Distance education in postindustrial society. In D. Keegan (ed.), Theoretical Principles of Distance Education. London: Routledge.

28. Presley, I. (2009). Assistive technology for students who are blind or visually impaired. New York: AFB.

29. Race, P. (1989). The Open Learning handbook. London: Kogan Page Ltd.

30. Robin, L. (2002). Predictors of Job-Seeking Behavior among Persons with Visual Impairments. In Journal of Visual Impairment \& Blindness, 96(9), (pp. 635-644). Retrieved from http://connection.ebscohost.com/c/articles/7432225/predictors-job-seeking-behavioramong-persons-visual-impairments

31. Skantzouri, A. (2008). Study with the subject of complete access of blind people and people with vision problems to electronic educational material. Diploma Thesis, Department of Humanist Studies, Patra.

32. Sperl, B. (2001). Developing library services to people with vision problems: a guide for Greek libraries. European Commission. Leonardo da Vinci Porgamme, Accelarate, Trainer Training Manual.

33. Support services for the Blind and Visual Impaired. (2012) Retrieved from http://www.lionsclubs.org/EN/our-work/sight-programs/index.php

34. Van Hasselt, V. (1988). Handbook of Developmental and Physical Disabilities. New York: Pergamon Press.

35. Willetts, G. (1993). Eye profile: the impact and total loss of sight on the resident population of the Western Health and Social Services Board and an evaluation of relevant services and facilities. London: RNIB.

36. Wolffe, K. and Candela, A. (2002). Expanding the labor pool: Recruiting, hiring, and maintaining workers with visual impairments. In Employment Relations Today, 29, (pp. 59-68).

37. Yin, R.K. (1989). Case Study Research: design and methods. London: Sage. 